\title{
Sonoelastographic Features of Major Salivary Gland Tumors and Pathology Correlation
}

\author{
Mustafa Farasat, ${ }^{1}$ Gulgun Yilmaz Ovali, ${ }^{2}$ Fatih Duzgun,, ${ }^{2,}$ Gorkem Eskiizmir,, Serdar Tarhan, ${ }^{2}$ and Ayca \\ $\operatorname{Tan}^{4}$ \\ ${ }^{1}$ Department of Radiology, Manisa Merkez Efendi Government Hospital, Manisa, Turkey \\ ${ }^{2}$ Department of Radiology, Faculty of Medicine, Celal Bayar University, Manisa, Turkey \\ ${ }^{3}$ Department of Ear, Nose and Throat, Faculty of Medicine, Celal Bayar University, Manisa, Turkey \\ ${ }^{4}$ Department of Pathology, Faculty of Medicine, Celal Bayar University, Manisa, Turkey \\ "Corresponding author: Fatih Duzgun, Department of Radiology, Faculty of Medicine Celal Bayar University, Manisa, Turkey. Tel: +90-5052529663, Fax: +90-2362349070, E-mail:
} fatihdzgn@yahoo.com

Received 2016 December 04; Revised 2017 March 08; Accepted 2017 March 22.

\begin{abstract}
Objectives: To investigate the diagnostic efficiency of elastography in differentiation of malignant and benign tumors by evaluating salivary gland masses in means of their elastography scores and strain ratios.

Patients and Methods: Twenty five patients with salivary gland mass lesions were detected through B- mode ultrasonography, Doppler ultrasonography, strain elastography and their strain ratios were calculated. The results were compared with histopathologic results.

Results: Twenty five patients had 27 lesions consisting of seven malignant and 20 benign lesions. Mann Whitney U test, ROC analysis, Fisher test and Chi square tests were used statistically. Mean strain rates were calculated as $2.26 \pm 0.29$ in the benign group and $2.02 \pm 0.59$ in the malignant group. There was no statistically significant difference between the two groups $(\mathrm{P}=0.698)$. Elastography score was calculated as mean $2.4 \pm 0.94$ in the benign group and mean $2.28 \pm 0.38$ in the malignant group. There was no statistically significant difference between the two groups $(\mathrm{P}=0.708)$. Accepting the strain rate as 0.89 ; sensitivity of elastography in differentiating malignant from benign lesions is $71 \%$, and the specificity is $50 \%$. However, the area under the ROC curve is 0.55 , which is not statistically significant $(\mathrm{P}=0.699)$.

Conclusion: In conclusion, elastography is a supporting method for B-mode ultrasonography in the differentiation of benign and malignant salivary gland masses. However, the overlap of elastographic findings is evident in benign and malignant masses. Care should be taken to have tissues with similar stiffness under the reference tissue and the lesions in elastographic evaluation of the superficial mass. We have not met a study that has pointed out the importance of stiffness of the tissue located beneath the lesion that may affect the elastography results in the literature. In this respect our study is unique.
\end{abstract}

Keywords: Major Salivary Gland Tumors, Sonoelastography, Pathology

\section{Background}

Salivary gland tumors that are most frequently detected in the parotid gland present approximately $3 \%$ of all head and neck tumors (1). Of note, preoperative differentiation between malignant and benign salivary tumors is essential for surgical planning $(1,2)$.

Currently, ultrasonography(USG), computed tomography (CT) and magnetic resonance imaging (MRI) are the radiological techniques for imaging of salivary gland tumors. Despite the high sensitivity of these radiological techniques, the accuracy of predicting histopathology of salivary gland masses is lower than expected as morphologic characteristics of benign and malignant lesions may overlap frequently (1-7). In addition, they have several limi- tations in daily practice. Therefore, another approach with more accurate diagnostic rates is required.

Sonoelastography is a medical imaging modality that identifies elasticity of tissues with qualitative, quantitative and semi-quantitative techniques. Most of the malignant lesions are harder than benign lesions as they generally have desmoplastic reaction and fibrous parts. Elastography is mainly focused on this principle and aimed to determine stiffness/elasticity of the mass, thereby differentiating the nature of the lesions (7).

\section{Objectives}

The purpose of this study was to evaluate the diagnostic role of elastography for the differential diagnosis of be- 
nign and malignant salivary gland tumors using elastographic scores and strain ratios.

\section{Patients and Methods}

This prospective study was done in patients presenting with a palpable mass located within a salivary gland on physical examination and referred to the radiology department for ultrasound in a one year period between 2014 and 2015. The patients were examined with B mode and Doppler US and had lesions in the salivary gland. Patients under the age of 18 , solely deep lobe localization in the parotid gland, reactive and benign lymph nodes in the parotid gland, cystic abscess and vascular malformations were excluded. Lesions were examined by B-mode ultrasonography, Doppler ultrasonography and strain elastography. Toshiba Aplio 500, Tokyo, Japan ultrasonography and $8-13 \mathrm{MHz}$ lineer transducer was used. All the data of patients were recorded in the picture archiving and communication system (PACS). The shape, size, margin, echo type, vascularity and gray scale findings were examined by B mode ultrasound and Doppler ultrasonography. The longest diameter of the tumor was measured. Sonography was always performed before the biopsy and/or surgery. Rhythmic manual compression was applied on the lesion which was centrally located and the transducer was held strictly perpendicular to the skin to obtain the sufficient symmetrical sinusoidal curve. The vertical amplitude of the probe was between 1 and $2 \mathrm{~mm}$; and the mean speed of the probe movement was once or twice per second during the compressions. All lesions were scored on elastograms in terms of their stiffness compared to normal parenchyma using a 4-grade system like the grading presented by Dumiriu et al. (Table 1) (8).

Table 1. Description of Sonoelastography Scores

\begin{tabular}{ll}
\hline Score & Description \\
\hline $\mathbf{1}$ & $\begin{array}{l}\text { Mass is similar in elasticity to surrounding glandular parenchyma; } \\
\text { with a mixture of green, yellow and red areas }\end{array}$ \\
$\mathbf{2}$ & $\begin{array}{l}\text { Mass is predominantly soft compared with adjacent parencyhma, } \\
\text { with some areas of stiffness representing < 50\%of tumor area }\end{array}$ \\
$\mathbf{3}$ & $\begin{array}{l}\text { Mass is predominantly stiff, but areas of elasticity are still present; } \\
\text { stiffness is present over }>50 \% \text { of tumor area }\end{array}$ \\
\hline $\mathbf{4}$ & $\begin{array}{l}\text { Mass is entirely stiff(ranging from light blue to dark blue on } \\
\text { elastogram) }\end{array}$ \\
\hline
\end{tabular}

Strain ratio values of all the lesions were calculated individually. Strain ratio defined the ratio of the elasticity of salivary gland lesions and the surrounding normal salivary gland tissue. First range of interest(ROI) was placed to contain most of the tumor; whereas, the second ROI was located in the normal glandular tissue with the same depth. Scoring of sonoelastographic images and strain ratio calculations were evaluated by two radiologists who were not aware of the histopathologic diagnosis.

Excisional biopsy or parotidectomy was performed on 24 of 25 patients, while one was examined with tru-cut biopsy. For the histopathological examination, slides containing $5 \mu \mathrm{m}$ thick sections were examined by staining hematoxylin and eosin. Histochemical and immunohistochemical studies were performed when necessary for diagnosis. Elasticity scores and strain ratio calculations were compared with histopathologic results.

\section{Results}

Twenty benign tumors ( 13 pleomorphic adenoma, six Warthin's tumor, one myoepitelioma) and seven malignant tumors (two adenoid cystic carcinoma, one malignant melanoma, one squamous cell carcinoma metastasis, one lymphoma, one oncocytic cell carcinoma, and one adenocarcinoma) were included in the study. There was only one case with bilateral involvement who was diagnosed as Warthin's tumor.

Twenty-five tumors were located in the parotid gland; whereas, only two tumors were in the submandibular gland. Eleven of the patients were female, while fourteen of them were male. Only one out of seven malignant tumors was found in a female patient. The age interval of the study group was between 21 and 83 (average age, $51.96 \pm$ 1.91).

The long axis dimension of 27 tumors were between 6 and $48 \mathrm{~mm}$. (mean $27.1 \mathrm{~mm}$ ). Thickness of the tumors were between 8 to $46 \mathrm{~mm}$ (mean 32.5). Distance of the evaluated masses from the skin was between 2 and $7 \mathrm{~mm}$ (mean 3.98). Eleven out of 27 cases comprised a cystic component (five pleomorphic adenoma, three Warthin's tumor, one metastatic lymph node, one lymphoma, and one myoepitelioma). The echogenity, structure, margin, shape and vascularity characteristics of the masses that have been observed in US and Doppler US are shown in Table 2 .

Lobulated contour was defined in $65 \%$ of benign lesions and $57.1 \%$ of malignant ones. Ovoid contour was defined in $35 \%$ benign lesions compared to $28.6 \%$ in malignant ones. Results were statistically not significant for differentiation ( $\mathrm{P}=\mathbf{0 . 2 2 6})$. Blurred edge was defined in two (28.6\%) malignant lesions and there were none in benign lesions. The results were statistically insignificant ( $P$ $=0.06$ ).

The strain ratios of tumors have been calculated with the mean of $2.26 \pm 0.29$ in benign tumors, and $2.02 \pm 0.59$ 
in malignant tumors (Table 3). There was no statistically significant difference between the two groups $(\mathrm{P}=0.698)$. Elastography score was calculated as mean $2.4 \pm 0.94$ in benign tumors and mean $2.28 \pm 0.38$ in malignant tumors. There was no statistically significant difference between the two groups $(\mathrm{P}=0.708)$. Receiver operating characteristic (ROC) analysis demonstrated a strain rate of 0.89 with a sensitivity rate of $71 \%$, and specificity rate of $50 \%$. However, the area under the ROC curve was 0.55 , which is not statistically significant $(\mathrm{P}=0.699)$. Elastographic maps according to histologic types of tumors are presented in Figures 1 - 4 and Table 4 .

Table 3. Mean Scores and Ratio Values of Benign and Malignant Masses

\begin{tabular}{lccc}
\hline & Histology & N & Mean \pm Std Deviation \\
\hline \multirow{2}{*}{ Ratio } & Benign & 20 & $2.26 \pm 0.22$ \\
& Malignant & 7 & $2.02 \pm 0.59$ \\
\multirow{2}{*}{ Score } & Benign & 20 & $2.40 \pm 0.94$ \\
& Malignant & 7 & $2.28 \pm 0.38$ \\
\hline
\end{tabular}

\section{Discussion}

Ultrasonography, CT and MRI are the primary radiological modalities for imaging of major salivary gland tumors. Although these modalities are highly sensitive for these tumors, their certainty to foresee histology is low because morphologic characteristics of benign and malignant lesions may overlap $(1,2)$.

Surgical treatment is determined depending on the characteristics of the lesion in salivary gland tumors. Superficial, total or radical parotidectomy and neck dissection are the treatment modalities when there is suspicion of malignancy. On the other hand, less invasive surgical techniques such as extracapsular dissection or partial parotidectomy is generally preferred for benign tumors (3, $4)$. Therefore, presuming the characteristics of the tumor before surgery is of utmost importance $(5,6)$.

Sonoelastography is a new imaging technique that determines the elasticity of the tissues in qualitative, quantitative and semi-quantitative manner (7). It is noteworthy that malignant tumors are generally harder than benign tumors as they have an intense fibrotic component and desmoplastic reaction. Elastography is developed based on this difference between benign and malignant tumors. Stiffness of the tissues are coded with different colors in real time by strain elastography qualitatively and elastographic scores are applied according to the ratio of the hard and elastic areas that they involve. In this study, the lesions were scored between 1 and 4 in terms of elastography after B mode US examination. The strain index ratios of the tumor and normal salivary gland parenchyma were calculated and semiquantitive values were obtained.

In previous studies, despite the fact that accuracy of elastography is low, real time elastography or shear wave elastography (SWE) displayed malignant tumors harder than benign tumors $(8,9)$. A couple of studies reported significant overlap between the stiffness of pleomorphic adenomas and malignant tumors. Tatar et al. reported that malignant parotid tumors were the hardest salivary gland tumors. Moreover, the elasticity of pleomorphic adenoma and malignant tumors were similarly hard. On the other hand, Warthin's tumor was softer in elastography (9). Our study was in concordance with Tatar et al. we showed that the hardest lesions were pleomorphic adenomas (mean: 2.70) where malignant ones were similarly hard (mean: 2.02) and Whartin's tumors were solely soft (mean: 1.58).

Dumitriu et al. studied 70 salivary gland tumors. The elastographic image was heterogeneous for most of the tumors. However, elastographic findings which were identified in most of the pleomorphic adenomas have also been observed in a significant portion of malignant tumors. Therefore, the typical elastographic pattern for pleomorphic adenomas could not be identified. The most specific finding they showed was lobulated contour which has not been seen in other benign tumors, but rarely seen in some malignant tumors (10). In another study conducted by Dumitriu et al. they examined 74 salivary gland tumors (18 malignant and 56 benign tumors) and determined that elastography was useful for the differentiation of benign and malignant tumors, but it was not successful in differentiating pleomorphic adenoma versus malignant tumors or pleomorphic adenoma versus Warthin's tumor (8). Despite the results of the study performed by Dumitriu et al. our study showed that benign- malignant differentiation is not significant $(\mathrm{P}=0.650$ for score, $\mathrm{P}=0.968$ for ratio). Also pleomorphic adenoma versus Whartin's tumor differentiation was not significant $(\mathrm{P}=0.82$ for ratio, $\mathrm{P}=0.77$ for score).

Bhatia et al. carried out a study on 65 parotid and submandibular gland mass lesions performed with qualitative elastography US. The authors concluded that this technique is weak for differentiating benign lesions especially pleomorphic adenoma from malignant ones (11). Moreover, they evaluated 60 focal salivary gland tumors where five of them were malignant using SWE and found significant overlap between benign tumors (median stiffness: $18.3 \mathrm{kPa}$ ) and malignant tumors (median stiffness: $13.5 \mathrm{kPa}$ ). However, pleomorphic adenoma was observed to be harder than Warthin's tumor (12).

Klintworth et al. evaluated 57 parotid mass lesions with 

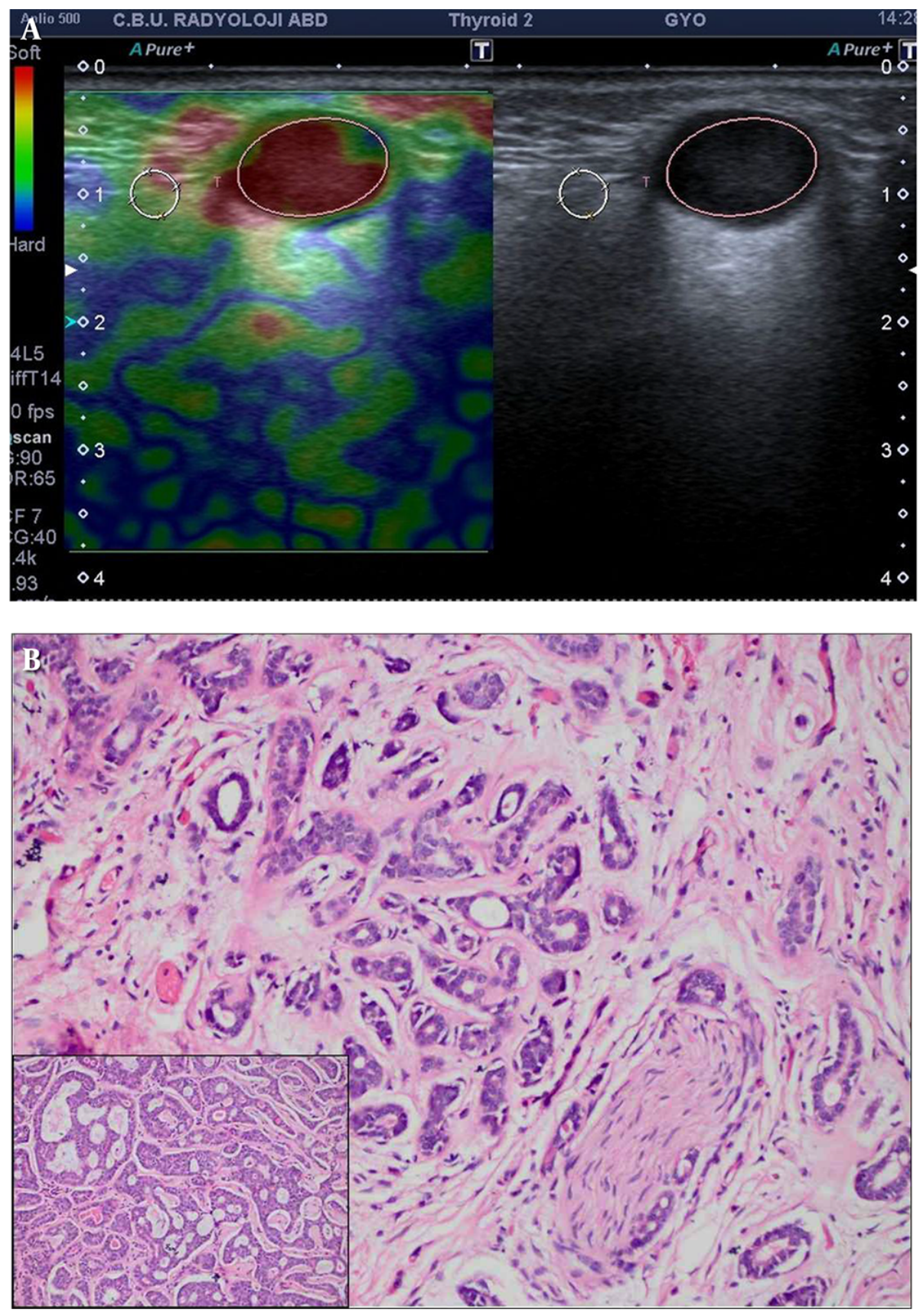

Figure 1. A, Adenoid cystic carcinoma: well-defined ovoid shaped hypoechoic solid mass with central vascularization in left parotid gland mass which appears entirely soft on the color elastogram; Strain ratio: 0.61, score of 1 lesion. B, Infiltrating neoplasm with tubular growth pattern and striking peri- and intraneural invasion (H\&E $\times 200)$; inset: cribriform and tubular growth patern with intraluminal eosinophilic to basophilic hyaline material (H\&E $\times 200)$.

US and US elastography and claimed that blurred edge is the sole criteria to differentiate malignant and benign tumors from each other in B mode US (13). Blurred edge was defined in $28.6 \%$ of malignant lesions where there was not any in benign lesions in our study, but this finding was not statistically significant $(\mathrm{P}=0.06)$.

The most distinctive limitation of this study was the low number of malignant cases. We observed that the mandibular bone effects elastographic score and strain ratio. It also has been observed that the lesions on the 

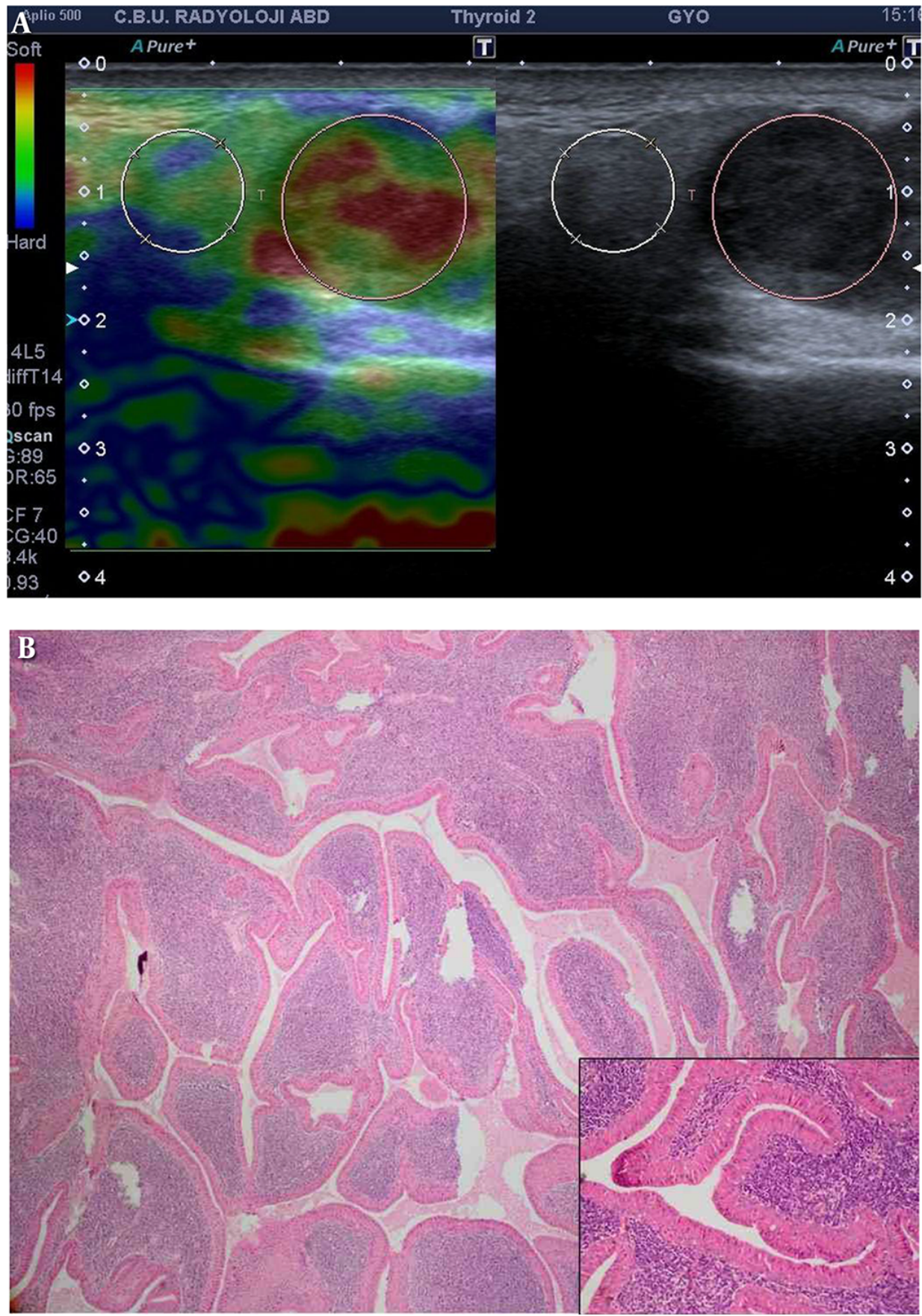

Figure 2. A, Warthin's tumor: cystic degenerated lobulated hypoechoic solid mass with mixed type vascularization in left parotid gland mass which is predominantly soft. Strain ratio: 0.46 , score of 1 . B, The tumor is characterized by cystic and papillary appearance with lymphoid proliferation (H\&E $\times 40$ ); inset: papillary projections are lined by oncocytic epithelium which composed of double cell layer $(\mathrm{H} \& \mathrm{E} \times 200)$.

mandible stretch more and change their shapes as they do not have any space to go deeper during compression. If the lesion is located in the parotid gland overlying the mandible bone, and the ROI is placed in parotid gland not over the mandible, the lesion will be softer than it really is as it will stretch more compared to the reference region. On the contrary, if the lesion is placed in a no-bone neighboring area in the parotid gland, and the reference ROI 

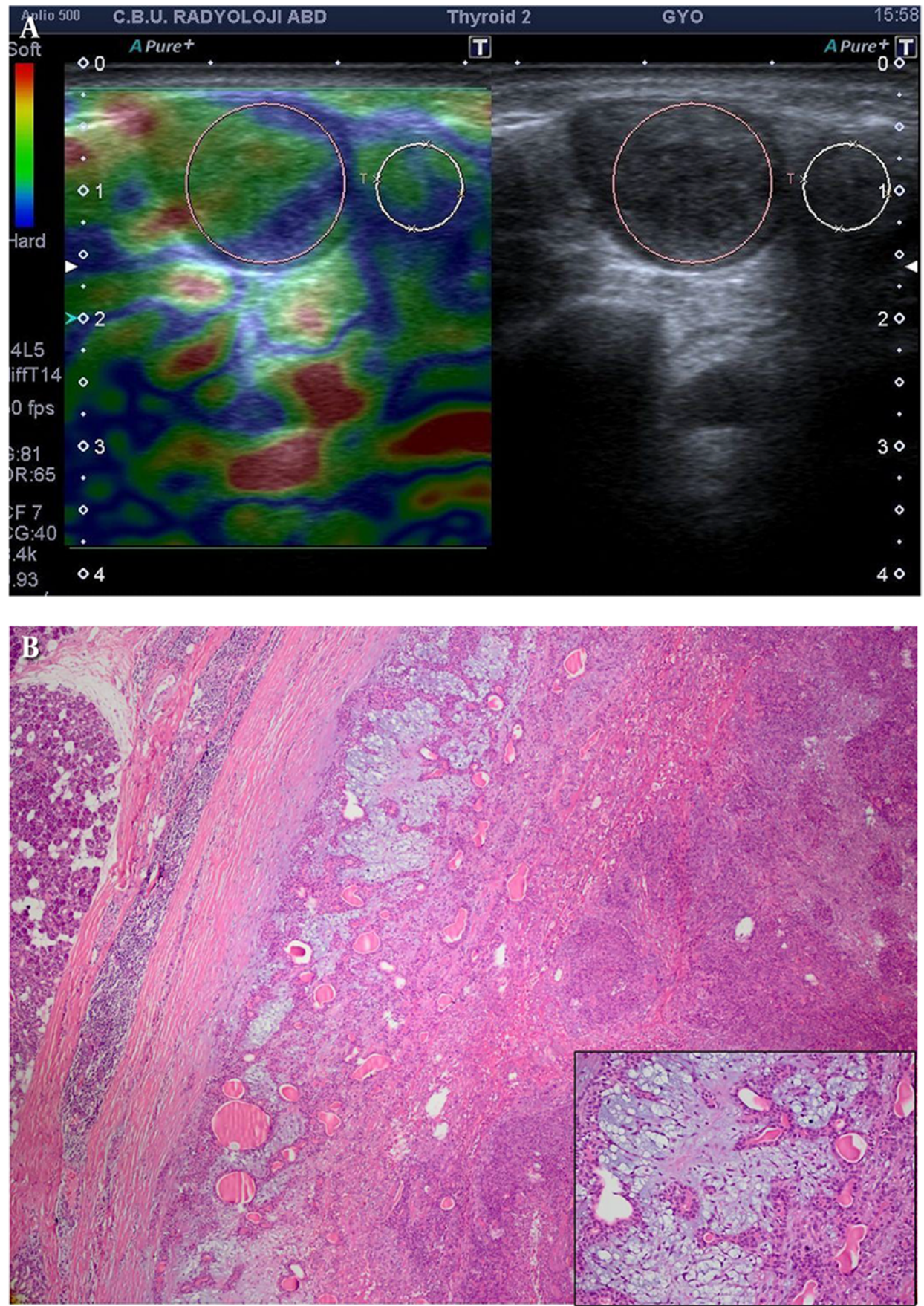

Figure 3. A, Pleomorphic adenoma: well-defined ovoid shaped and heterogeneous hypoechoic solid mass with milimetric cystic degenerations in left parotid gland mas which is predominantly soft. Strain ratio: 0.81 , score of 2 lesion. B, Encapsulated and sharply demarcated tumoral lesion is composed of tubules, ductules and matrix stroma $(\mathrm{H} \& \mathrm{E} \times 40)$; inset: myxoid stroma is remarkable admixed with acini and tubules (H\&E $\times 200)$.

is placed in the gland close to the mandible, the lesion strain index will be higher, which means that it will be observed harder than it actually is, as the normal tissue will act more flexible than it is. Therefore, attention should be paid to have tissues on the same level and with similar stiffness or softness. Otherwise, false positive or negative findings will be obtained. The nearby location with the mandible also restricts compression with the right angle. 


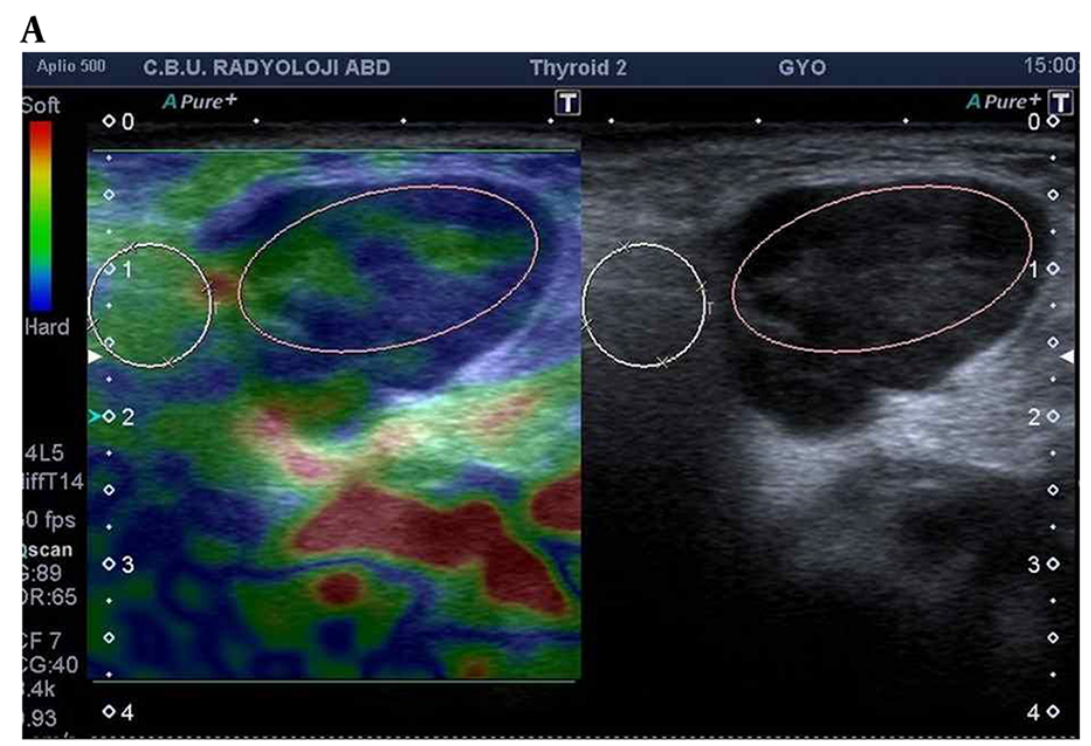

B
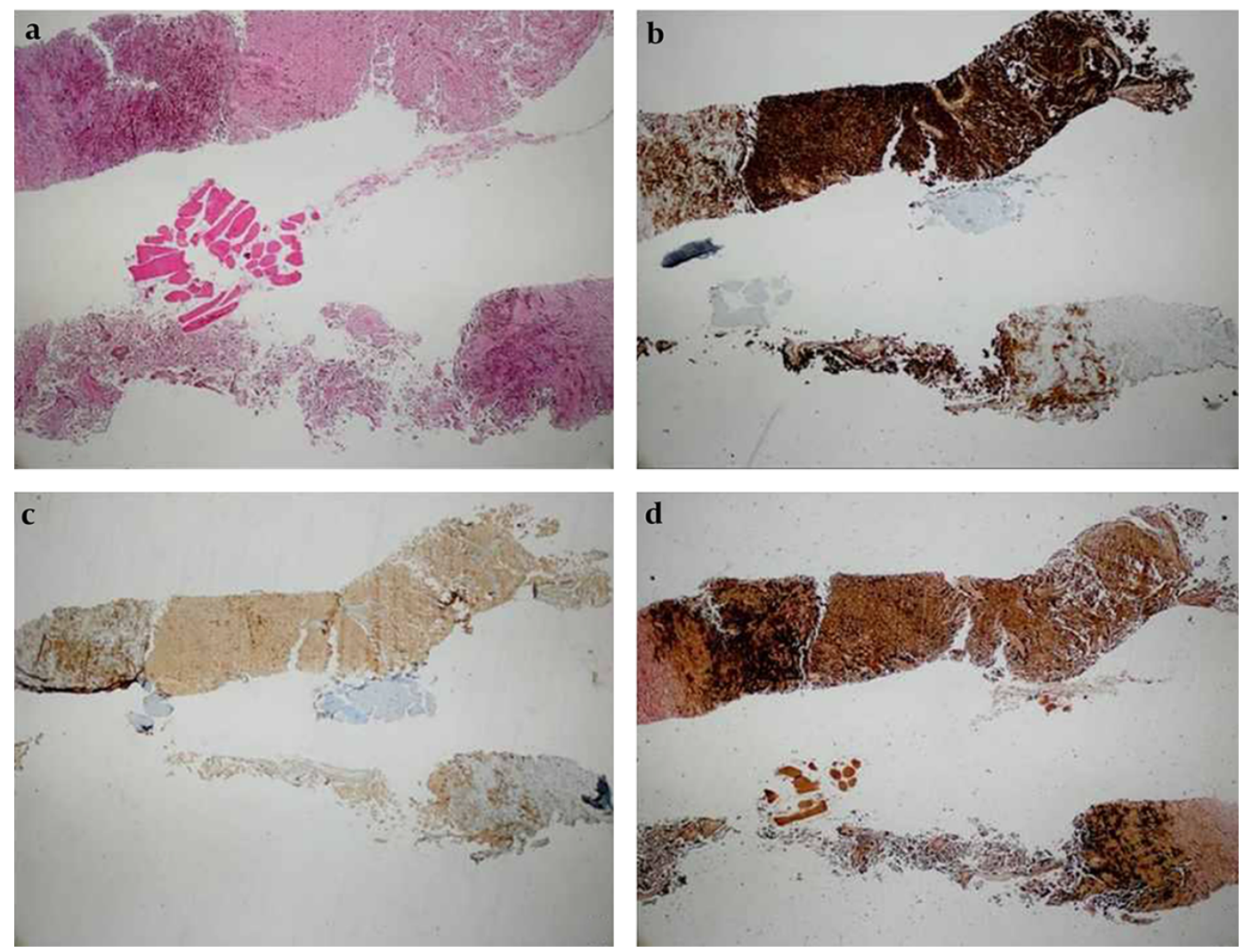

Figure 4. A, Malignant melanoma: well-defined hypoechoic solid mass with mixed type vascularization in right parotid gland mass which stiff (blue) areas represent more than $50 \%$ of tumor. Strain ratio: 2.1, score of 3. B, The core biopsy consists of scattered tumor cells staining positivity with HMB-45, Melan-A and Fontana-Masson, B(a), H\&E $\times$ 40, B(b), HMB-45 $\times 40, \mathrm{~B}(\mathrm{c})$, Melan-A $\times 40, \mathrm{~B}(\mathrm{~d})$, Fontana-Masson $\times 40$.

Insufficient compression limits the usage of elastography.

A tumor with whole gland coverage is another limitation 
Table 4. Elastographic Visual Score According to the Histological Type of Tumors

\begin{tabular}{|c|c|c|c|c|c|}
\hline & \multirow[t]{2}{*}{ Histology } & \multicolumn{4}{|c|}{ Elastographic visual score } \\
\hline & & ES 1 & ES 2 & ES 3 & ES 4 \\
\hline \multirow{3}{*}{ Benign } & Myoepithelioma $(\mathrm{n}=1)$ & 1 & - & - & - \\
\hline & Pleomorphic adenoma $(n=13)$ & 2 & 6 & 2 & 3 \\
\hline & Warthin's tumor $(n=6)$ & - & 3 & 3 & - \\
\hline \multirow{6}{*}{ Malignant } & Adenocystic carcinoma $(n=2)$ & 2 & - & - & - \\
\hline & Oncocytic cell carcinoma $(n=1)$ & - & - & 1 & - \\
\hline & Malignant melanoma $(\mathrm{n}=1)$ & 1 & - & - & - \\
\hline & Metastatic lymph node(n=1) & - & 1 & - & - \\
\hline & Lymphoma $(\mathrm{n}=1)$ & - & - & - & 1 \\
\hline & Adenocarcinoma $(\mathrm{n}=1)$ & - & - & - & 1 \\
\hline
\end{tabular}

which limits reference ROI placement. Tumefactive lesions invading dermis also limit appropriate contact with the probe. Deeper location of the normal gland parenchyma is another limitation for the lesion and the reference tissue should be at the same depth.

In conclusion, elastography is a supporting method for B-mode ultrasonography in the differentiation of benign and malignant salivary gland masses. However, overlap of elastographic findings is evident in benign and malignant masses. The current study involves a small number of malignant lesions, so further studies are required with larger series. It should be considered to have tissues with similar stiffness under the reference tissue and the lesions, in the elastographic evaluation of the superficial mass. We have not met a study that has pointed out the importance of stiffness of the tissue located beneath the lesion that may affect the elastography results in the literature. In this respect our study is unique.

\section{Footnotes}

Declaration of Conflicting Interests: The author(s) declared no potential conflicts of interest with respect to the research, authorship, and/or publication of this article.

Funding/Support: The author(s) received no financial support for the research, authorship, and/or publication of this article.

Ethical Approval: The study was granted waiver of ethical approval by the institution's Ethics and research committee.

\section{References}

1. Som PM BM. Salivary glands: Anatomy and Pathology. Salivary glands: Anatomy and Pathology In: Som PM, Curtin H. . 4nd ed. 2003. p. 205260.
2. Bozzato A, Zenk J, Greess H, Hornung J, Gottwald F, Rabe C, et al. Potential of ultrasound diagnosis for parotid tumors: analysis of qualitative and quantitative parameters. Otolaryngol Head Neck Surg. 2007;137(4):642-6. doi: 10.1016/j.otohns.2007.05.062. [PubMed: 17903584].

3. Klintworth N, Zenk J, Koch M, Iro H. Postoperative complications after extracapsular dissection of benign parotid lesions with particular reference to facial nerve function. Laryngoscope. 2010;120(3):484-90. doi 10.1002/lary.20801. [PubMed: 20112414].

4. Stennert E, Wittekindt C, Klussmann JP, Guntinas-Lichius O. New aspects in parotid gland surgery. Otolaryngol Pol. 2004;58(1):109-14 [PubMed: 15101269].

5. Koch M, Zenk J, Iro H. Long-term results of morbidity after parotid gland surgery in benign disease. Laryngoscope. 2010;120(4):724-30. doi: 10.1002/lary.20822. [PubMed: 20205175].

6. Burke CJ, Thomas RH, Howlett D. Imaging the major salivary glands. Br J Oral Maxillofac Surg. 2011;49(4):261-9. doi: 10.1016/j.bjoms.2010.03.002. [PubMed: 20381221].

7. Yerli H, Yilmaz T, Kaskati T, Gulay H. Qualitative and semiquantitative evaluations of solid breast lesions by sonoelastography. J Ultrasound Med. 2011;30(2):179-86. [PubMed: 21266555].

8. Dumitriu D, Dudea S, Botar-Jid C, Baciut M, Baciut G. Real-time sonoelastography of major salivary gland tumors. AJR Am J Roentgenol. 2011;197(5):W924-30. doi: 10.2214/AJR.11.6529. [PubMed: 22021543].

9. Tatar IG, Ergun O, Kurt A, Sahin M, Hekimoglu B. The role of elastosonography in the differentiation of parotid gland lesions: report of three cases and review of the literature. Pol J Radiol. 2014;79:398401. doi: 10.12659/PJR.891019. [PubMed: 25386225].

10. Dumitriu D, Dudea SM, Botar-Jid C, Baciut G. Ultrasonographic and sonoelastographic features of pleomorphic adenomas of the salivary glands. Med Ultrason. 2010;12(3):175-83. [PubMed: 21203593].

11. Bhatia KS, Rasalkar DD, Lee YP, Wong KT, King AD, Yuen HY, et al. Evaluation of real-time qualitative sonoelastography of focal lesions in the parotid and submandibular glands: applications and limitations. Eur Radiol. 2010;20(8):1958-64. doi: 10.1007/s00330-010-1756-0. [PubMed: 20407904].

12. Bhatia KS, Cho CC, Tong CS, Lee YY, Yuen EH, Ahuja AT. Shear wave elastography of focal salivary gland lesions: preliminary experience in a routine head and neck US clinic. Eur Radiol. 2012;22(5):957-65. doi: 10.1007/s00330-011-2364-3. [PubMed: 22200901].

13. Klintworth N, Mantsopoulos K, Zenk J, Psychogios G, Iro H, Bozzato A Sonoelastography of parotid gland tumours: initial experience and identification of characteristic patterns. EurRadiol.2012;22(5):947-56. doi: 10.1007/s00330-011-2344-7. [PubMed: 22270139] 


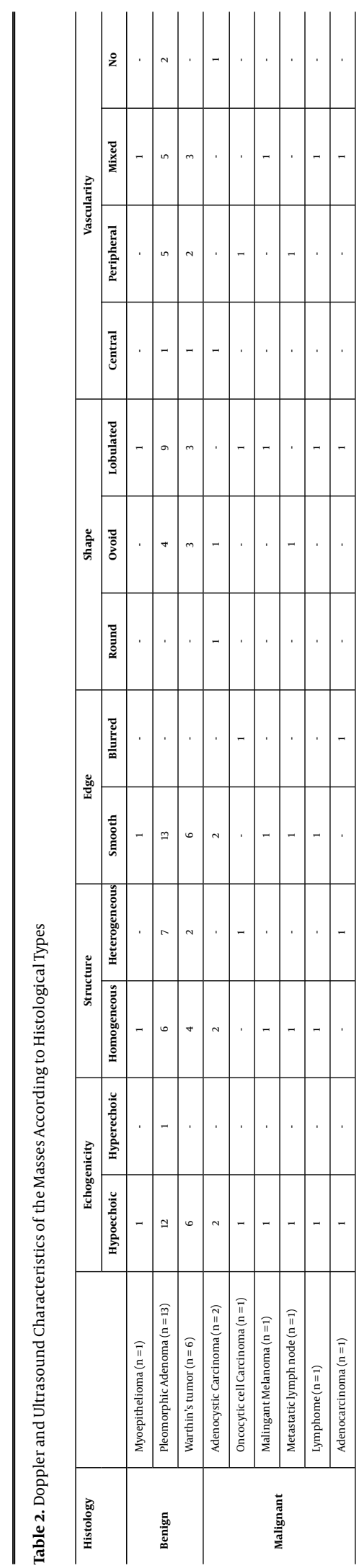

